\title{
Secondary dapsone-resistant leprosy in Brazil: a preliminary report
}

\author{
MARIA HELENA DOS SANTOS DAMASCO, \\ S TALHARI,* S M VIANA, M SIGNORELLI, \\ M H F SAAD \& L M C ANDRADE \\ Laboratório de Hanseníase da Fundação Oswaldo Cruz, Rio de \\ Janeiro, Brasil; *Centro de Dermatologia Tropical Alfredo da \\ Mata-Manaus, Brasil
}

Accepted for publication 10 July 1985

\begin{abstract}
Summary In this first report of laboratory confirmation of the presence of dapsone-resistant Mycobacterium leprae in Brazil, the susceptibility to dapson was studied in 12 patients clinically suspected of being resistant to dapsone.

The results showed that $8 / 12$ strains were fully resistant to dapsone $(66 \%)$, and $3 / 12$ strains were partially resistant $(25 \%)$. In $1 / 12$ case the organisms failed to grow in all groups of mice. Important indicators for dapsone resistance include irregular treatment, lepromata of the histoid variety, bacterioscopy with solid bacilli and lack of response to dapsone therapy during 6 months.
\end{abstract}

\section{Introduction}

Due to its efficacy, good safety margin, good acceptance by the patients and low cost, leprosy chemotherapy in Brazil has been based on dapsone monotherapy since 1943. However, this fact is creating a dangerous epidemic situation owing to the emergence of drug-resistant strains. Patients become subject to relapses and disseminate strains of dapsone-resistant $M$. leprae to their contacts.

The first clinical evidence of dapsone resistance was reported in $1953 .{ }^{1}$ But because of the difficulty of finding a suitable test animal, laboratory confirmation was only obtained in $1964^{2}$ when Shepard's food-pad technique was used for demonstrating drug resistance.

In $1977^{3}$ primary dapsone resistance was confirmed for the first time.

Dapsone resistance, which can be partial or total, appears late; never before 5 years, generally from 10 to 15 years, and sometimes after 20 years of regular treatment.

When resistance is partial, the multiplication of $M$. leprae can only be observed when minimal doses of $1-2 \mathrm{mg} / \mathrm{kg}$ of the body weight of the drug are 
used. When bacterial multiplication occurs with this dosage we can consider dapsone resistance as total.

The World Health Organization ${ }^{4}$ suggested that efforts should be made to provide leprosy-endemic countries with well-equipped laboratories for Shepard's foot-pad technique.

Cases where there is clinical suspicion of dapsone resistance should be confirmed by the foot-pad technique, in order to facilitate better planning of therapeutic schemes and better supervision of the treatment of individual patients.

Research in 25 countries has indicated dapsone-resistant coefficients of prevalence in the order of $1-19$, and of incidence in the order of $0 \cdot 1-0.8 \%$ per year. ${ }^{4}$

In view of such variable data, a survey of dapsone-resistant cases is justifiable in Brazil as multidrug therapy is more expensive and more toxic and requires monitoring programmes which increase the costs to the health services.

To carry out such a survey the Oswaldo Cruz Foundation set up a laboratory for Shepard's foot-pad technique and the first results of our experience are presented here.

\section{Materials and methods}

Biopsy specimens were obtained from patients with multibacillary leprosy attending the Centro de Dermatologia Tropical Alfredo da Mata in Manaus (Brazil), and suspected of secondary resistance to dapsone. Employing the technique described by Shepard, ${ }^{5} M$. leprae were recovered from each specimen and diluted so as to provide an inocslum of $5 \times 10^{3} \mathrm{M}$. leprae per foot-pad. Forty $\mathrm{BALB} / \mathrm{c}$ mice were inoculated in the right-hind foot-pad. Beginning on the day of inoculation a group of 10 mice were fed ordinary mouse diet (Control group), whereas the other 3 groups were fed a diet which incorporated dapsone in a concentration of $0.0001,0.001,0.01 \mathrm{~g} / 100 \mathrm{~g}$ diet. The dapsone concentration in the mouse diet was analysed by Ellard's Standard Method. ${ }^{6}$

Three months later, one mouse from the untreated group was sacrificed and $M$. leprae were harvested from the right foot-pad. When the average number of organisms reached $5 \times 10^{5}$ in the control group, one mouse of each treated group was sacrificed. If fewer than $5 \times 10^{5}$ organisms per foot-pad were harvested from the untreated mice, the experiment was continued until a concentration of $5 \times 10^{5}$ was reached. At this time all mice of the other groups were sacrificed and the results compared.

\section{Results}

The susceptibility to dapsone of $12 \mathrm{M}$. leprae strains was tested in the mouse footpad and the results are summarized in Table 1. 
Table 1. Average number of Mycobacterium leprae per foot-pad $\left(\times 510^{5}\right)$

\begin{tabular}{|c|c|c|c|c|c|c|c|c|c|c|}
\hline \multirow[b]{2}{*}{ Patient } & \multirow[b]{2}{*}{ Sex } & \multirow[b]{2}{*}{ Age } & \multirow[b]{2}{*}{ Class } & \multirow[b]{2}{*}{$\mathrm{BI}$} & \multirow{2}{*}{$\begin{array}{l}\text { Date mice } \\
\text { inoculated }\end{array}$} & \multirow{2}{*}{$\begin{array}{c}\text { Time of } \\
\text { harvest } \\
\text { (days) }\end{array}$} & \multicolumn{4}{|c|}{ Dapsone concentration $(\mathrm{g} \%)$} \\
\hline & & & & & & & 0 & 0.0001 & $0 \cdot 001$ & $0 \cdot 01$ \\
\hline MCV & $\mathrm{F}$ & 46 & MHD & $3+$ & $07 / 07 / 82$ & 214 & $4 \cdot 6$ & 50 & 1.6 & 0.7 \\
\hline JBM & $\mathbf{M}$ & 50 & MHD & $3+$ & $08 / 07 / 82$ & 274 & $8 \cdot 9$ & $6 \cdot 9$ & $7 \cdot 9$ & $9 \cdot 9$ \\
\hline $\mathrm{VC}$ & $\mathrm{M}$ & 44 & MHV & $3+$ & $08 / 07 / 82$ & 214 & $1 \cdot 0$ & $0 \cdot 9$ & $0 \cdot 7$ & 0.7 \\
\hline FPC & $\mathrm{M}$ & 53 & MHV & ND & $09 / 07 / 82$ & 277 & $6 \cdot 9$ & $9 \cdot 9$ & 10 & $9 \cdot 9$ \\
\hline MLS & $\mathbf{M}$ & 47 & MHV & $2+$ & $13 / 07 / 82$ & 244 & 11 & $7 \cdot 9$ & 10 & $7 \cdot 9$ \\
\hline JWSL & $\mathbf{M}$ & 33 & MHV & $4+$ & $07 / 10 / 82$ & 212 & $5 \cdot 2$ & $1 \cdot 4$ & $1 \cdot 3$ & $1 \cdot 2$ \\
\hline MGCS & $\mathrm{F}$ & 38 & MHV & ND & $13 / 12 / 82$ & 242 & $\mathrm{NM}$ & NM & NM & NM \\
\hline WPA & $\mathbf{M}$ & 33 & MHV & $3+$ & $21 / 01 / 83$ & 224 & 10 & 19 & 25 & 10 \\
\hline MDM & $\mathrm{F}$ & 33 & MHV & $3+$ & $22 / 02 / 83$ & 223 & 16 & 10 & 10 & 85 \\
\hline SFC & $\mathbf{M}$ & 34 & MHV & $2+$ & $22 / 02 / 83$ & 223 & 24 & $6 \cdot 6$ & 39 & 10 \\
\hline APL & $\mathrm{M}$ & 30 & MHV & $3+$ & $18 / 04 / 83$ & 213 & $5 \cdot 0$ & 10 & 20 & 80 \\
\hline LBS & M & 32 & MHV & $3+$ & $09 / 05 / 83$ & 201 & 22 & $7 \cdot 8$ & 47 & 46 \\
\hline
\end{tabular}

As the table shows the $M$. leprae strains from 8 patients were fully resistant to dapsone, since $M$. leprae multiplied as well in the treated mice as in the untreated mice.

$M$. leprae strains from 3 patients showed partial resistance to dapsone, that is the organisms did not grow so well in the group of treated mice as in the group of untreated mice.

The organisms obtained from patient MGCS failed to multiply either in the mice of the treated or in those of the untreated (control) group.

\section{Discussion}

This was the first attempt to demonstrate dapsone-resistant strains of M. leprae, in Brazil, by Shepard's mouse foot-pad technique.

As has been shown in other countries, our results, demonstrating that $8 / 12$ strains were fully resistant to DDS (66\%), and that $3 / 12$ strains were partially resistant $(25 \%)$, indicate the existence of mixed populations of dapsone-resistant and dapsone-susceptible strains. In 1/12 strains the organisms failed to grow in either treated or untreated mice indicating that they were already dead when inoculated. Possible explanations for this could be that the organisms had lost their viability during packing and transportation or during the preparation of the inoculum; or the organisms might have been killed in the patient ${ }^{7}$ in the course of treatment and might therefore be considered as susceptible to dapsone. 
Some indicators are very suggestive of dapsone resistance-irregular treatment, lepromata of the histoid variety, bacterioscopy with solid bacilli and no response to dapsone treatment during 6 months.

\section{References}

1 Wolcott RR, Ross H. Exacerbation of leprosy during present day treatment. Int J Lepr, 1953; 21: 437.

${ }^{2}$ Pettit JHS, Rees RJW. Sulphone resistance in leprosy: an experimental and clinical study. Lancet, 1964; 2: 673-4.

3 Pearson JH, Haile GSa, Rees RJW. Primary dapsone resistant leprosy. Lepr Rev, 1977; 48: 12932.

${ }^{4}$ WHO. Technical Report Series 675. 1982; 27.

5 Shepard CC. The experimental disease that follows the injection of human leprosy bacilli into foot-pads of mice. J exp Med, 1960; 112: 445-54.

${ }^{6}$ Ellard GA. Assaying dapsone in mouse diets. Lepr Rev, 1980: 51: 321-3.

7 Utji R, Kosasih A, Santoso AV. Dapsone resistant leprosy in Jakarta: a preliminary report. Lepr Rev, 1983; 54: 193-5. 